\title{
Risk Factors for Development of Broncho- Ostructive Syndrome in Children
}

\author{
Sh. M. Ibatova, F. Kh. Mamatkulova, N. B. Abdukadirova, Yu. A. Rakhmonov, \\ M. M. Kodirova
}

Sci. Journal Impact

Factor: $6.1(2018)$

ICV: 90.90 (2018)

(c) (i) (8)

Samarkand State Medical Institute, Uzbekistan.

Copyright@IJCRR

\section{ABSTRACT}

Introduction: Respiratory diseases today are one of the urgent problems of paediatrics and occupy the first place in the structure of child morbidity and mortality.

Objective: The study aimed to identify the main risk factors for the development of broncho-obstructive syndrome in young children based on the data of the Samarkand Branch of the Republican Scientific Center for Emergency Medical Aid.

Methods: Assessment of risk factors for the development of broncho-obstructive syndrome was carried out using statistical methods in epidemiological analysis. We carried out a retrospective analysis of 912 case histories of children with the bronchoobstructive syndrome at the age of 1 to 3 years. General analysis of blood, urine, faeces, X-ray examinations of the chest organs, pulse oximetry data and expert opinions.

Result: Biofeedback developed against the background of acute obstructive bronchitis was diagnosed in 494 (54.2\%) children as compared to $418(45.8 \%)$ patients in other group. Studies have shown that risk factors are cases of exudative forms of atopic dermatitis (39.1\%), lymphatic-hypoplastic diathesis (19.5\%), prematurity $61(9.4 \%)$, with acute obstructive bronchitis -46 , and with acute bronchitis - 15 children. Disharmonious physical development was noted (in 223 children, $36.4 \%$ ) due to an increase in body weight above the 90th percentile.

Conclusion: Main risk factors for the development of broncho-obstructive syndrome are children over a year old, winter and spring seasons of the year, perinatal encephalopathy, aggravated allergic anamnesis, protein-energy malnutrition, part trophy, food allergy, early transfer of children to artificial feeding, hereditary and congenital pathology of the bronchopulmonary system and others. All this dictates the need for preventive work in families and family clinics for the prevention of bronchial asthma in the future.

Key Words: Broncho-obstructive syndrome, Risk factors, Children, Retrospective analysis, Pneumonia, Acute obstructive bronchitis, Bronchial asthma

\section{INTRODUCTION}

Diseases of the respiratory system today are one of the urgent problems of paediatrics and occupy the first place in the structure of childhood morbidity and mortality. ${ }^{1,2}$ In young children, acute pneumonia and bronchitis are widespread, which occur with the broncho-obstructive syndrome and often cause an unfavourable outcome of the underlying disease in a child. Broncho-obstructive syndrome is a symptom complex that is clinically manifested by paroxysmal cough, expiratory dyspnea, asthma attacks and is associated with impaired bronchial patency of functional or organic origin. ${ }^{2,3}$
By itself, it has a characteristic clinical picture, so there are no difficulties with its diagnosis.

Especially clinically, broncho-obstructive syndrome manifests itself in children in the first years of life, which is due to the anatomical and physiological characteristics of the respiratory system: narrowness of the airways, insufficient elasticity of the lungs, softness of the cartilage of the bronchial tree, insufficient rigidity of the chest, a tendency to develop oedema, hypersecretion of viscous mucus, poor development smooth muscles of the bronchi. ${ }^{4,5}$ Faced with the broncho-obstructive syndrome in infants in practice, the

\section{Corresponding Author:}

Sh. M. Ibatova, Samarkand State Medical Institute, Uzbekistan.

ISSN: 2231-2196 (Print)

Received: 25.07 .2020
ISSN: $0975-5241$ (Online)

Revised: 18.09 .2020
Accepted: 12.11 .2020 
doctor, as a rule, makes a diagnosis of obstructive bronchitis or bronchiolitis, occurring with symptoms of respiratory failure, developing more often against the background of Arvi..$^{6-8}$

The emergence and development of broncho-obstructive syndrome are influenced by various factors and, above all, respiratory infection, obstructing $5 \%$ to $40 \%$ of cases. ${ }^{7,9}$ Risk factors for the development of bronchial obstruction in children are: toxicosis of pregnancy, complicated childbirth, hypoxia in childbirth, prematurity, aggravated allergic history, rickets, protein-energy malnutrition, perinatal encephalopathy, early artificial feeding, past respiratory diseases at an early age, hereditary and pathology of the bronchopulmonary system and an unfavourable state of the external environment. ${ }^{10}$ Predicting asthma at an early age continues to be difficult. In some studies, up to twothirds of children with bronchial asthma had no symptoms of bronchial obstruction at an early age $\mathrm{e}^{11,12}$ and, accordingly, these children had a late diagnosis of bronchial asthma. ${ }^{13-14}$

\section{MATERIALS AND METHODS}

Assessment of risk factors for the development of broncho-obstructive syndrome was carried out using statistical methods in epidemiological analysis. We carried out a retrospective analysis of 912 cases of case histories of children with broncho-obstructive syndrome aged 1 to 3 years who were hospitalized in the intensive pediatric department of the SFRNCEMP for the period from 2016 to 2019.

To assess the risk factors for the development of the disease, we conducted studies that included a thorough analysis of complaints, anamnestic data of patients, general examination data, the results of physical research methods, general clinical laboratory, immunological, microbiological and instrumental research methods according to standard methods, taking into account anthropometric data and mass growth indicators. All the data we received from archival materials were entered into specially designed maps.

To diagnose the syndromological features of the disease, data from paraclinical research methods were used: general analysis of blood, urine, faeces, X-ray examinations of the chest organs, pulse oximetry data and expert opinions.

Biofeedback developed against the background of acute obstructive bronchitis was diagnosed in 494 (54.2\%) children (group 1). In the comparison group, the diagnosis of acute bronchitis without symptoms of bronchial obstruction was ascertained in 418 (45.8\%) patients (group 2) (Table 1).

Table 1: Distribution of examined patients by nosology

\begin{tabular}{llll} 
No & $\begin{array}{l}\text { Nosological forms of dis- } \\
\text { eases }\end{array}$ & Total & \\
Group 1 & $\begin{array}{l}\text { Acute obstructive bronchitis } \\
\text { with the broncho-obstructive } \\
\text { syndrome }\end{array}$ & 494 & 54.2 \\
Group 2 & $\begin{array}{l}\text { Acute bronchitis without the } \\
\text { broncho-obstructive syndrome }\end{array}$ & 418 & 45.8 \\
Total & & 912 & 100 \\
\hline
\end{tabular}

Among them, infants made up 499 (54.7\%), children from 1 to 3 years old made up 277 (30.4\%) and children from 3 to 5 years old - $136(14.9 \%)$. Among all surveyed boys there were only $540(59.2 \%)$, girls - $372(40.8 \%)$ (Table 2$)$.

Table 2: Distribution of examined patients by age and sex

\begin{tabular}{|c|c|c|c|c|c|c|c|c|c|}
\hline \multirow[t]{3}{*}{ Gender of children } & \multirow[t]{3}{*}{ Groups } & \multicolumn{6}{|c|}{ Agestructure } & \multicolumn{2}{|c|}{ Total } \\
\hline & & \multicolumn{2}{|c|}{2 month - 1 year } & \multicolumn{2}{|c|}{1 - 3 years } & \multicolumn{2}{|c|}{ 3- 5 years } & \multirow[b]{2}{*}{$\mathbf{N}$} & \multirow[b]{2}{*}{$\%$} \\
\hline & & $\mathbf{n}$ & $\%$ & $\mathbf{n}$ & $\%$ & $\mathbf{n}$ & $\%$ & & \\
\hline \multirow{2}{*}{$\begin{array}{l}\text { Boys total } 540 \\
(59,2 \%)\end{array}$} & 1 & 165 & 50.8 & 103 & 31.7 & 57 & $17 \cdot 5$ & 325 & 65.8 \\
\hline & 2 & 124 & $57 \cdot 7$ & 59 & 27.4 & 32 & 14.9 & 215 & 51.4 \\
\hline \multirow{2}{*}{$\begin{array}{l}\text { Girls total } 372 \\
(40,8 \%)\end{array}$} & 1 & 94 & 55.6 & 54 & 31.9 & 21 & 12.5 & 169 & 34.2 \\
\hline & 2 & 116 & 57.1 & 61 & 30.0 & 26 & 12.9 & 203 & 48.6 \\
\hline Total & & 499 & 54.7 & 277 & 30.4 & 136 & 14.9 & 912 & 100 \\
\hline
\end{tabular}

In the group of children with broncho-obstructive syndrome against the background of acute obstructive bronchitis, the number of boys was 325 , where there was a clear predominance of it over girls ( $65.8 \%$ and $34.2 \%$, respectively). In the second group, among children with acute bronchitis, there were 215 boys ( $51.4 \%)$, girls - 203 (48.6\%), i.e., there was no significant difference in the sex of the patients. As shown in Table 2, among all examined patients, children under 1 year of age suffered from broncho-obstructive syndrome and acute bronchitis more often (54.7\%) than older children (1-3 years - $30.4 \%$; $3-5$ years $-14.9 \%$ ). 
Among all children who were hospitalized in the period from 2012 to 2015 , the following seasonality of this disease was noted. So, most often children with acute obstructive bronchitis were admitted in winter (201 patients) and spring (175 patients). In autumn, 102 patients were admitted and in summer only 56 patients. And if in relatively cold and humid periods of the year the increase in the incidence of acute obstructive bronchitis can be compared with the increase in the activity of the corresponding viral infections, then in the summer period the role of pollen and food allergies as a risk factor for the development of broncho-obstructive syndrome is possible.

Studying the seasonality of acute bronchitis, we found the following - in the winter months of the year, 161 patients were admitted, in the spring - 132, in the fall - 86 and in the summer - 39 patients. Similarly, an increase in the incidence of acute bronchitis in winter is also associated with an increase in the viral activity of pathogens.

Repeated cases of acute respiratory infection (6 times or more) during the year were observed in $212(42.9 \%)$ patients with acute obstructive bronchitis. In the majority of children with acute obstructive bronchitis (358 patients - 72.5\%) deficiency states and aggravated premorbid background were revealed: $313(63.4 \%)$ children were early transferred to artificial feeding, $278(56.3 \%)$ had a history of revealed a perinatal lesion of the central nervous system, 222 (45\%) rickets and 481 (97.3\%) - anaemia.

Most of the babies were born full-term 851 (90.6\%) babies and had a bodyweight of more than 2500 grams. There were only 61 premature babies $(9.4 \%)$, with 46 children with acute obstructive bronchitis, and 15 children with acute bronchitis. In half of the examined children with acute obstructive bronchitis, there was a violation of physical development. At the same time, high and disharmonious physical development was more common (in 223 children, 36.4\%). Figure 1 shows the frequency of manifestations of various anamnestic data in sick children with acute obstructive bronchitis.

\section{RESULTS AND DISCUSSION}

A retrospective analysis of archival material showed that the development of acute respiratory failure by the type of bronchial obstruction in patients with acute. ${ }^{28,29,30}$ Obstructive bronchitis depends on a combination of many factors, age differences, the presence of concomitant diseases, their combination, risk factors, etc.

The work carried out has shown that constitutional abnormalities are also a risk factor, in particular cases of exudative forms of atopic dermatitis (39.1\%), lymphatic-hypoplastic diathesis $(19.5 \%)$. Most of the babies were born full-term $851(90.6 \%)$ babies and had a bodyweight of more than 2500 grams. There were only 61 premature babies (9.4\%), with 46 children with acute obstructive bronchitis, and 15 children with acute bronchitis.

In half of the examined children with acute obstructive bronchitis, there was a violation of physical development. At the same time, high and disharmonious physical development was more common (in 223 children, 36.4\%) due to an increase in body weight above the 90th percentile. Low and disharmonious physical development was recorded in 98 (13.9\%) children due to a decrease in body weight below the 10th percentile.

According to our data, physical symptoms of bronchial obstruction in acute obstructive bronchitis were observed in all children. Frequent and productive cough occurred in $1 / 3$ of children (36.4\%), and rare, more often in the morning, in the remaining $2 / 3(63.5 \%)$ of patients, which is associated with insufficient mucociliary clearance in this age period. ${ }^{15-17}$

Organ-specific symptoms and data from X-ray research methods turned out to be more informative in the diagnostic and differential-diagnostic terms. So, dry cough at the onset of the disease, with a further transition to a wet cough, was noted in all patients with acute obstructive bronchitis and acute bronchitis. Wet cough with the discharge of viscous, mucopurulent sputum or vomiting was noted in the case histories of $303(61.3 \%)$ patients with acute obstructive bronchitis and $264(63.2 \%)$ patients with acute bronchitis. Noisy wheezing and expiratory dyspnea, as clear signs of bronchial obstruction of the lower airways (respectively, in $460-93.1 \%$ and $448-90.6 \%$ ) were detected only in patients with acute obstructive bronchitis, in contrast to patients in the control group with acute bronchitis, in which this symptomatology was not recorded in the medical history. ${ }^{15,18}$

\section{CONCLUSIONS}

Thus, the main risk factors for the development of bronchoobstructive syndrome are children over one-year-old, winter and spring seasons of the year, perinatal encephalopathy, aggravated allergic anamnesis, protein-energy malnutrition, part trophy, food allergy, early transfer of children to artificial feeding, hereditary and congenital pathology of the bronchopulmonary system. and others. All this dictates the need for preventive work in families and family clinics for the prevention of bronchial asthma in the future.

\section{REFERENCES}

1. Babushkina AV, Babushkina AV. Acute respiratory viral diseases and broncho-obstructive syndrome. Ukrainian Med J 2011; 81(1): 69-74.

2. RaghuRaman TS, Singh D, Jayaprakash DG, Raja LN. Airway obstruction in children. Med J Armed Forces India 1995 Apr; 51(2): 87-90. 
3. Volkov IK, Volkov IK. Differential diagnosis of broncho-obstructive syndrome in children. Med Emerg Cond 2013; 48(1): 125-128.

4. Belevsky AS. Global strategy for the treatment and prevention of bronchial asthma (revision 2011)/ ed. Ros. respirator 2012:109.

5. Zaykov SV. Broncho-obstructive syndrome: principles of diagnosis and therapy. Ukrain Pulmonol J 2009; 1: 45-49.

6. Ibatova SM, Baratova RSh. Assessment of risk factors for the development of broncho-obstructive syndrome in children. Prob Bio Med 2016; 4 (91): 39-42.

7. Kazachkov MI. Etiology and differential diagnosis of chronic cough in children. Russ Bull Perinatol Pediatr 2013; 58 (3): $54-$ 61.

8. Ibatova SM. Broncho-obstructive syndrome in young children: prevalence, clinical manifestations, diagnosis and treatment. Prob Bio Med 2017;2(94):178-181.

9. Athanazio R. Airway disease: similarities and differences between asthma, COPD and bronchiectasis. Clinics (Sao Paulo) 2012 Nov; 67(11): 1335-1343.

10. Patrusheva YS. Diagnostics and treatment of acute bronchiolitis in children. Diagn Pediatr 2011; 3(1): 5-11.

11. Soroka YA. Broncho-obstructive syndrome in pediatric practice. Child Health 2006; 2(2): 5-14.
12. Soroka YA. Artificial feeding as one of the risk factors for the development of broncho-obstructive syndrome in young children. Child Health 2012; 7(42): 60-62.

13. Khaptkhaeva GE. Respiratory infection and bronchial asthma. Pulmonology 2008; 5: 75-79.

14. Ait-Khaled N, Enarson DA, Bissell K. Access to inhaled corticosteroids is key to improving quality of care for asthma in developing countries. Allergy 2007; 62(3): 230-236.

15. Duijvestijn YCM, Mourdi N, Smuchny J, Pons G, Chalumeau M. Acetylcysteine and carbocysteine for acute upper and low respiratory tract infections in paediatric patients without the chronic bronchopulmonary disease (Review). Cochrane Database Syst Rev 2010; 9: 1-22.

16. KD van de Kant, Klaassen EM, Jobsis Q. Early diagnosis of asthma in young children by using non-invasive biomarkers of airway inflammation and early lung function measurements: study protocol of a case-control study. BMC Public Health 2009; 9: 210.

17. Frey U. The challenge of managing wheezing in infants. N Engl J Med 2009; 360(20): 2130-2133.

18. Chalumeau M, Cheron G, Assathiany R, Moulin F. Mucolytic agents for acute respiratory tract infections in infants: pharmacoepidemiologic problem. Arch Pediatrie 2002;9: 1128-1136. 